\title{
Pemanfaatan M-Retailing dengan Dukungan Layanan Cash on Delivery pada Swalayan
}

\author{
The use of M-Retailing with Cash on Delivery Service Support \\ in Supermarket
}

Gat

STMIK Pontianak

E-mail: gutsy1802@gmail.com

\begin{abstract}
Abstrak
Mengkombinasikan bisnis dengan penerapan teknologi informasi sudah menjadi kebutuhan pasar diera digitalisasi saat ini. Penggunaan teknologi mobile dalam mendukung kegiatan bisnis sudah menjadi tren diaat banyak orang memiliki mobilitas sangat tinggi. Berbelanja menggunakan perangkat mobile sudah menjadi hal yang biasa dikalangan masyaratkat, namun penggunaan perangkat mobile untuk kegiatan berbelanja kebutuhan seharihari di pasar swalayan masih belum terlihat. Seharusnya ini bisa dijadikan sebagai inovasi baru bagi pemilik bisnis pasar swalayan dalam rangka meningkatkan layanan yang lebih luas. Tujuan penelitian ini adalah menghasilkan sistem mobile retailing yang dapat dipergunakan untuk berbelanja pada pasar swalayan. Sistem ini hanya dapat dipergunakan bagi masyarakat yang menggunakan perangkat smartphone. Dengan menggunakan Jquery Mobile Framework dan Web service, penelitian ini berhasil menghadir sistem mobile retailing dimana dengan sistem ini masyarakat dapat menggunakannya untuk memesan barang yang ada di salah satu toko swalayan. Metode pembayaran yang berlaku adalah Cash On Delivery dimana pembayaran dilakukan secara langsung oleh konsumen setelah konsumen mendapatkan barang yang dipesan dengan baik. Pembayaran jasa antar barang ke konsumen diluar sistem ini dan menjadi tanggung jawab pemilik usaha.
\end{abstract}

Kata Kunci - Retailing, Web Service, Mobile, Smartphone, Sistem

\begin{abstract}
Combine business with the application of information technology has become a market need in the current era of globalization. Then use of mobile technology in business support become a trend where people have highest mobilization. Shopping using mobile devices has become commonplace in society, yet the use of mobile devices for daily shopping activities in supermarket is still not visible. This should be a new innovation for supermarket business owners in order to improve the broader service. The goal of this research is to produce a mobile retailing system which can be used for shopping at supermarket. This system can only be used for society who utilize the smartphone. Using JQuery Mobile Framework and web service, this research succeeded in produce mobile retailing system where with this system people can use it to order goods in one of the supermarkets. Cash On Delivery is the paying method used where the customers pay it directly after having the goods ordered good condition. Payment of intercompany services to consumers outside this system and the responsibility of the business owner.
\end{abstract}

Keywords - Retailing, Web Service, Mobile, Smartphone, System 


\section{PENDAHULUAN}

Era digitalisasi secara signifikan telah mempengaruhi tatanan bisnis dan ini menjadi suatu kesempatan bagi para pemilik usaha untuk merancang strategi baru dalam rangka meningkatkan keuntungan melalui pemanfaatan inovasi teknologi [1]. Salah satu teknologi informasi dan komunikasi yang saat ini telah merubah dan mempengaruhi setiap aspek kehidupan manusia adalah teknologi mobile. Terjadinya peningkatan jumlah pengguna teknologi mobile telah mendatangkan prospek bagi industri dalam menggunakan smartphone untuk meningkatkan pertumbuhan bisnis [2]. Salah satu bidang bisnis yang dapat dijalankan dengan bantuan teknologi mobile adalah retail (eceran). Retailing merupakan semua kegiatan penjualan barang dan jasa secara langsung kepada konsumen akhir untuk tujuan pemakaian sendiri dan rumah tangga tanpa ada unsur keperluan bisnis [3]. Situs Online Retail telah banyak dikembang sebagai terobosan baru dalam menawarkan barang dan jasa kepada konsumen secara online. Namun dengan semakin banyaknya kompetisi layanan online, perusahaan mulai memanfaatkan peluang dari kehadiran teknologi mobile [4]. Penggunaan teknologi mobile dalam retail adalah merupakan cara yang dapat dipergunakan bagi pemilik usaha untuk menarik perhatian konsumen agar dapat terlibat di dalam toko [5]. Bentuk keterlibatan konsumen yang memiliki pengaruh terhadap pertumbuhan bisnis adalah penggunaan perangkat mobile yang didukung oleh koneksi internet untuk melakukan kegiatan belanja [6]. Pemakaian teknologi mobile sangat efektif dalam kegiatan berbelanja karena dengan teknologi ini dapat memberikan kemudahan dalam pencarian, kenyamanan pasca pembelian, mobilitas dan fleksibilitas dari perangkat mobile tersebut $[7,8,9]$. Pertumbuhan internet dewasa ini sangat berperan dalam pergeseran paradigma perilaku konsumen terhadap belanja online dan ini sekaligus menjadi pemicu pada pertumbuhan online retailing [10]. Belanja online dapat memberikan lingkungan retailing yang inovatif dimana melalui internet retailer dapat menawarkan produk mereka serta layanannya kepada konsumen [11].

Penelitian ini berfokus pada bagaimana sistem mobile retailing dapat dipergunakan oleh konsumen dalam kegiatan pembelian barang pada pasar swalayan tanpa harus mendatangi pasar swalayan tersebut. Sistem mobile retailing hanya dapat dioperasikan pada pasar swalayan yang sudah menyediakan akses barang secara online. Metode pembayaran yang berlaku pada sistem mobile retailing adalah Cash On Delivery dimana tujuan dari layanan ini sebagai upaya untuk memberikan keyakinan kepada konsumen yang pada umunya masih ragu dengan barang yang dijual secara online. Sistem pembayaran Cash On Delivery semakin banyak diminati hal ini dikarenakan konsumen merasa aman, privasi identitas terjaga dan dapat menguji kualitas produk sebelum melakukan pembayaran [12]. Sistem mobile retailing dan Cash On Delivery merupakan salah satu wujud dari pelayanan yang diberikan oleh pemilik pasar swalayan kepada konsumen. Dengan bentuk layanan seperti ini diharapkan bisa memberikan kepuasan dan kenyamanan kepada konsumen. Banyak literatur yang mendukung bahwa peran dari kualitas layanan yang diberikan memberikan pengaruh yang positif terhadap kepuasan konsumen [13,14] dan dapat dijadikan oleh konsumen dalam membuat keputusan melakukan pembelian kembali [15].

\section{METODE PENELITIAN}

Penelitian sistem mobile retailing berbentuk studi kasus yaitu pasar swalayan, operasional penjualan dan metode pembayaran Cash On Delivery pilihan kasus dengan satu pasar swalayan dijadikan sebagai contoh data. Metode penelitiannya Research \& Development (R\&D). Metode perancangan sistem mobile retailing menggunakan Rapid Application Development (RAD) yang merupakan sebuah strategi pengembangan sistem yang menekankan kecepatan melalui keterlibatan pengguna. Melibatkan pengguna pada proses desain menyebabkan kebutuhan pengguna dapat terpenuhi dengan baik dan secara otomatis kepuasan pengguna sebagai pengguna sistem semakin meningkat [16]. Pengumpulan data menggunakan teknik wawancara yang melibat pemakaian recorder untuk perekaman dan melakukan observasi terhadap operasional dan proses 
bisnis. Rancangan model sistem mobile retailing digambarkan dengan pemodelan berorientasi objek yaitu Unified Modelling Language(UML). Pada tahapan pengembangan sistem mobile retailing langsung melibat pihak manajemen pasar swalayan untuk dirumuskan kebutuhan dari pemilik bisnis sebagai penyedia produk. Sistem mobile retailing dibuat dengan menggunakan JQuery Mobile dan dikonversikan kedalam bentuk Extention Android (. apk) sehingga dapat dilakukan instalasi pada perangkat mobile. Data barang ditampilkan pada perangkat mobile dalam format XML (Extensible Markup Language) sebagai salah satu wujud dari penerapan Web Service. Pemilihan model perangkat lunak yang cocok untuk digunakan dalam sebuah organisasi sangat penting untuk keberhasilan proyek. Pemilihan salah satu model terhadap yang lain adalah didorong oleh ukuran proyek, anggaran, ukuran team dan banyak faktor lainnya [17].

\section{HASIL DAN PEMBAHASAN}

Mobile retaining merupakan suatu sistem yang dapat dipergunakan untuk melakukan pembelian produk pada pasar swalayan. Penggunaan sistem ini memungkinkan pemakai sistem dapat melakukan transaksi pembelian kebutuhan rumah tangga sesuai dengan produk yang ditawarkan suatu pasar swalayan. Setiap transaksi pembelian barang dilakukan dengan menggunakan perangkat mobile yang sudah dilakukan pemasangan sistem. Pemilik swalayan memberikan pelayanan dengan cara mem-packing setiap barang yang sudah dibeli oleh konsumen dan mengirimkan barang tersebut kealamat pembeli. Teknik pembayaran yang diterapkan adalah Cash On Delivery dimana konsumen mendapatkan produk terlebihdahulu kemudian melakukan pembayaran ditempat sesuai dengan nilai tagihan dari barang yang beli konsumen.

\subsection{Requirement Planning.}

Requirement Planning merupakan fase dimana pengguna sistem dan penganalisis bertemu untuk mengidentifikasikan tujuan-tujuan dari sistem serta untuk mengidentifikasikan syarat-syarat informasi yang ditimbulkan dari tujuan-tujuan tersebut. Fokus utama dalam fase ini adalah menyelesaikan masalah-masalah perusahaan dalam hal studi kasusnya adalah pasar swalayan. Meskipun teknologi informasi dan sistem bisa mengarahkan sebagian dari sistem yang diajukan, orientasinya akan selalu tetap pada upaya pencapaian tujuan-tujuan perusahaan. Pengembang sistem harus dapat mencari informasi untuk memenuhi kebutuhan sistem yang akan dibangun. Kegiatan pengumpulan data dilakukan dengan cara observasi dan studi dokumen yang merupakan salah satu cara untuk mendapatkan informasi dari permasalahan dan kebutuhan sistem mobile retailing yang dapat dijadikan sebagai solusi untuk memecahkan permasalahan tersebut. Penulis mendeskripsikan segala hal yang diperlukan dalam rangka pengembangan sistem mobile retailing. Untuk mempermudah pemahaman kebutuhan dari sistem, penulis membaginya kedalam dua jenis kebutuhan yaitu kebutuhan fungsional dan kebutuhan nonfungsional. Kebutuhan fungsional adalah kebutuhan yang berisi proses-proses apa saja yang nantinya dilakukan oleh sistem. kebutuhan nonfungsional adalah kebutuhan yang menitikberatkan pada properti prilaku yang dimiliki oleh sistem. Berikut ini adalah fitur-fitur yang diperlukan admin untuk mengelola sistem sistem mobile retailing:

1. Data Produk

Admin melakukan pengisian data barang agar data barang tersebut bisa akses oleh konsumen.

2. Data Perusahaan

Admin mengelola data perusahaan untuk memberikan kemudahan bagi konsumen dalam melakukan transaksi pembelian barang.

3. Kebijakan

Pengelolaan informasi kebijakan dimaksudkan agar konsumen melakukan transaksi dengan benar dan terarah sesuai dengan kebijakan.

4. Admin dapat melihat data pesanan konsumen sehingga bisa memenuhi permintaan konsumen dan melakukan packing terhadap barang untuk dikirim ke alamat konsumen. 
Konsumen adalah masyarakat umum yang pada umumnya memiliki kemampuan yang bervariasi terhadap penggunaan perangkat mobile. Oleh karena itu perlu mendapat perhatian khusus pada rancangan sistem mobile retailing agar bisa diakses dengan mudah. Berikut ini adalah kebutuhan dalam usulan rancangan antarmuka mobile retailing:

1. Tersedia fitur login bagi konsumen lama dan fitur untuk konsumen melakukan registrasi awal ketika konsumen baru pertama kali mengakses sistem. Informasi yang terdapat pada fitur ini memberikan kemudahan bagi pemilik pasar swalayan dalam mengenali konsumen mereka.

2. Fitur pemesanan barang menampilkan data barang dengan tambahan metode pencarian cepat agar konsumen dapat dengan mudah menemukan barang yang mereka butuhkan.

\subsection{Design}

Perancangan sistem mobile retailing hanya berfokus pada unsur-unsur kebutuhan seperti yang telah dijabarkan pada tahap perencanaan kebutuhan. Penyajian model dari arsitektur sistem mobile retailing bertujuan untuk memberikan kemudahan dalam pemahaman model sistem yang berfokus pada pengguna dan kebutuhan pengguna. Perancangan arsitektur sistem mobile retailing mempresentasikan framework dari sistem perangkat lunak yang dibangun. Deskripsi arsitektur mengadopsi spesifikasi sistem, model analisis, dan interaksi subsistem yang telah didefenisikan pada tahap analisis perencanaan kebutuhan yang ditujukkan pada Gambar 1.

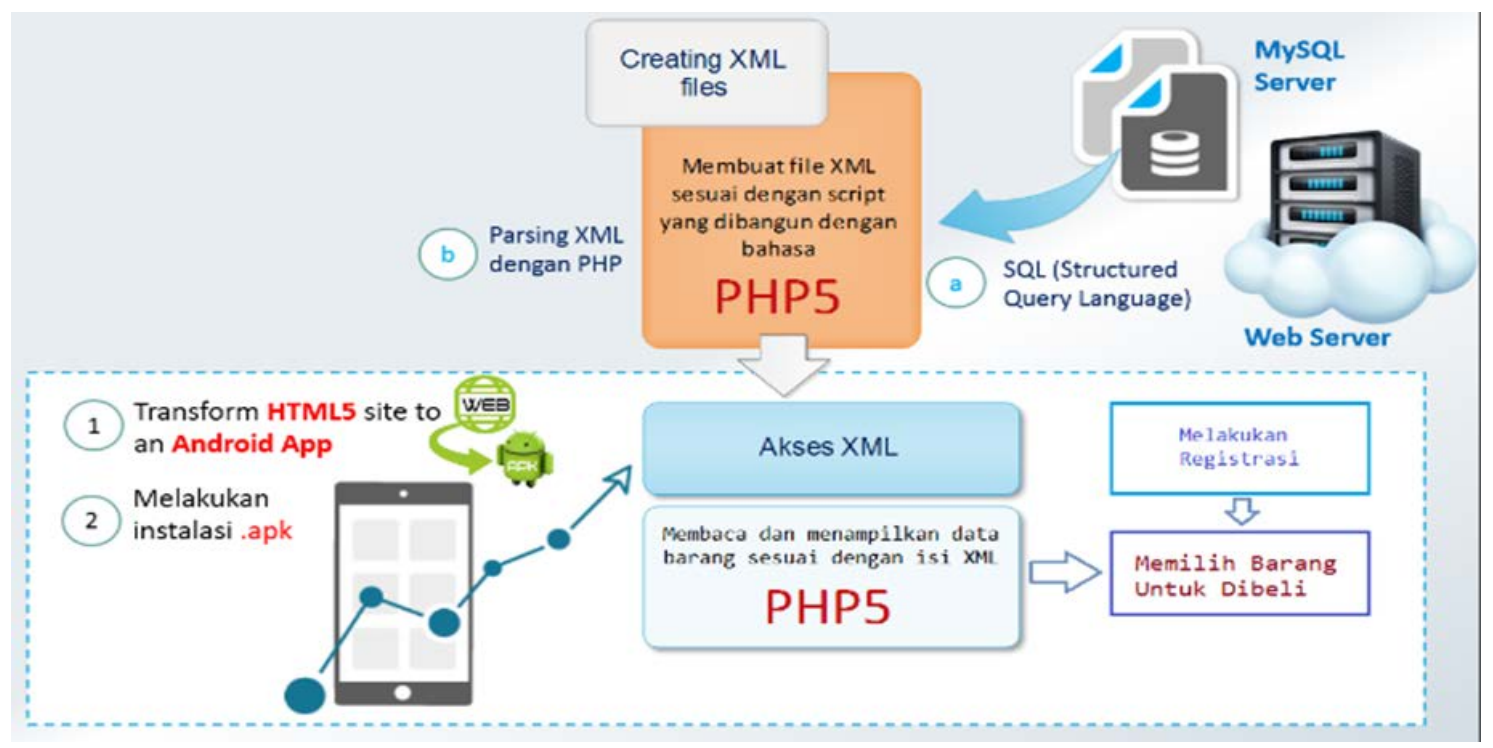

Gambar 1. Arsitektur Sistem Mobile Retailing

Perancangan model sistem mobile retailing mengacu kepada perancangan berbasis obyek yang disebut sebagai OOD (Object Orianted Design) dan dianggap menjadi strategi perancangan paling modern. Dalam penelitian ini penulis menggunakan model UML (Unified Modeling Language). Use case diagram menjelaskan manfaat sistem jika dilihat menurut pandangan orang yang berada di luar sistem atau actor. Gambar 2 menunjukkan diagram fungsionalitas suatu sistem atau kelas dan bagaimana sistem berinteraksi dengan dunia luar. Perancangan proses yang terjadi dalam sistem sistem mobile retailing dengan use case diagram. 


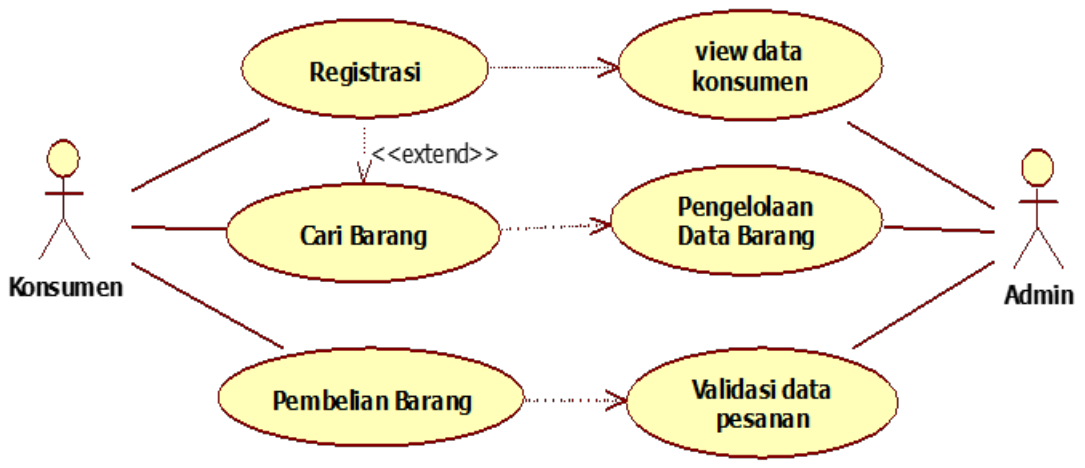

Gambar 2. Use case Diagram Sistem Mobile Retailing

Pada Gambar 2 use case diagram sistem mobile retailing memberikan gambaran dari proses singkat tentang interaksi aktor konsumen dengan sistem. Aktor konsumen beriteraksi dengan use case registrasi sebagai kegiatan untuk mendaftarkan diri pada sistem. Aktor konsumen melakukan pencarian barang yang selanjutnya melakukan interaksi dengan use case pembelian barang sebagai tahap akhir dalam kegiatan sistem. Sementara aktor admin berinteraksi dengan use case view data konsumen yang merupakan aktivitas untuk melihat biodata konsumen. Admin melakukan pengelolaan data barang untuk menyediakan akses terhadap data barang oleh konsumen. Admin berinteraksi dengan use case validasi data pesanan untuk merespon permintaan barang oleh konsumen.

Gambar 3 merupakan Activity Diagram memiliki pengertian yaitu lebih fokus kepada menggambarkan proses bisnis dan urutan aktivitas dalam sebuah proses yang dipergunakan untuk memperlihatkan urutan aktifitas proses bisnis yang sedang dirancang, bagaimana masing-masing alir berawal, decision yang mungkin terjadi, dan bagaimana mereka berakhir.

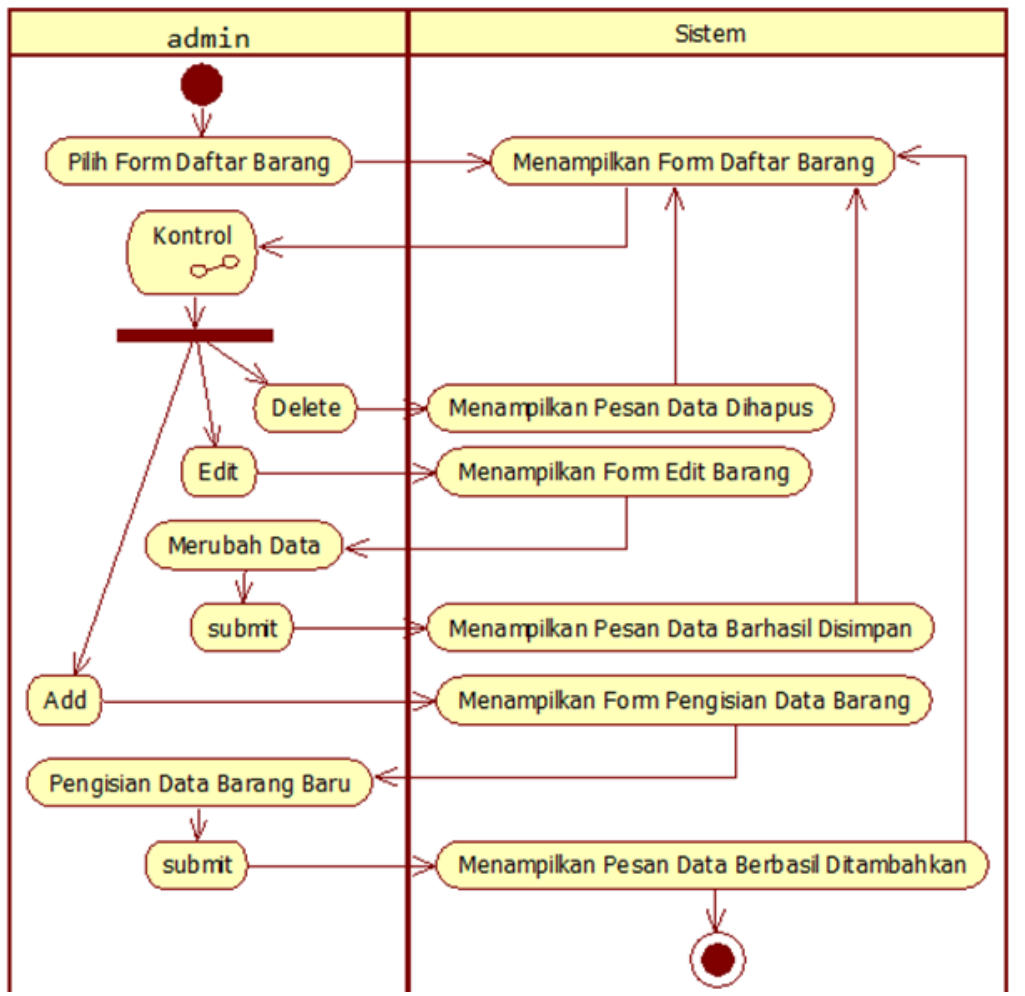

Gambar 3. Activity Diagram Kelola Data Barang 
Pada Gambar 3 Activity Diagram kelola data barang menjelaskan bahwa admin dapat melakukan pilihan penambahan, perubahan dan penghapusan data barang. Aktivitas ini merupakan hal yang sangat mendasar sebelum sistem bisa dipergunakan oleh konsumen yang ditunjukkan pada Gambar 4.

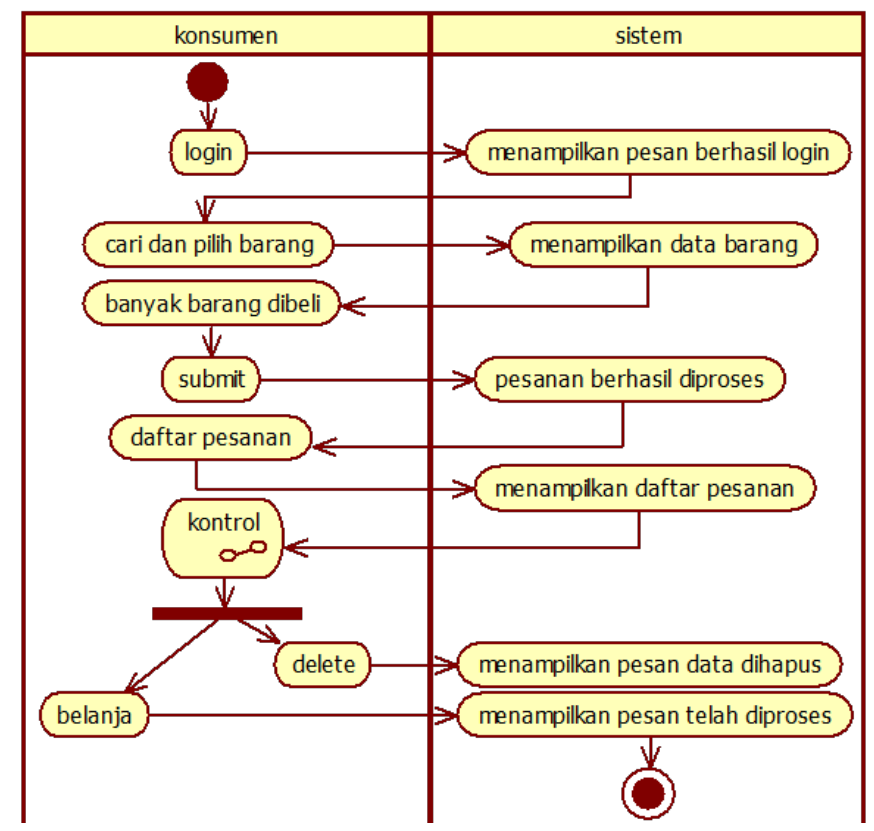

Gambar 4. Activity Diagram Pesanan Barang

Pada Activity Diagram pesanan barang dijelaskan bahwa dalam pemakaian sistem, konsumen telebih dahulu harus melakukan login sistem untuk proses verifikasi data konsumen. Konsumen dapat melakukan pencarian barang ketika sudah berhasil login. Konsumen memilih dan pesan barang dengan mengisikan jumlah kuantitas barang yang dipesan. Kegiatan pembelian dilakuakn secara terus menerus sesuai dengan jumlah item barang yang dibutuhkan. Sebagai langkah terakhir konsumen melakukan pengecekan terhadap barang yang telah dipesan dan selanjutkannya meneruskan belanja untuk poses akhir dari sistem. Pada gambar 5 menjelaskan Diagram Component dalam suatu peragkat lunak dipergunakan untuk menggambarkan struktur dan hubungan antar komponen dalam perangkat lunak (mobile retailing) tersebut termasuk juga ketergantungan di antara komponen-komponen. Komponen dapat juga berupa interface, yaitu kumpulan layanan yang disediakan sebuah komponen untuk komponen lain.

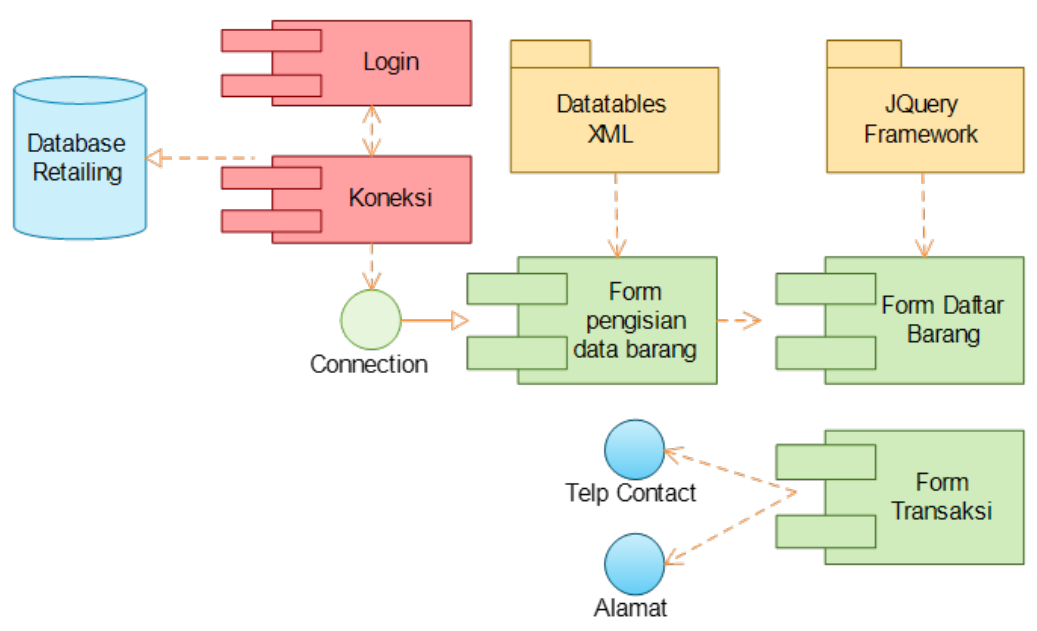

Gambar 5. Component Diagram Mobile Retailing 
Gambar 6 adalah diagram hubungan entitas yang merupakan suatu dokumentasi data dengan mengidentifikasi entiti data dan memperhatikan hubungan yang ada diantara entiti. Pembuatan diagram hubungan entitas hanya menampilkan tabel yang memiliki keterkaitan dengan tabel yang lainnya.

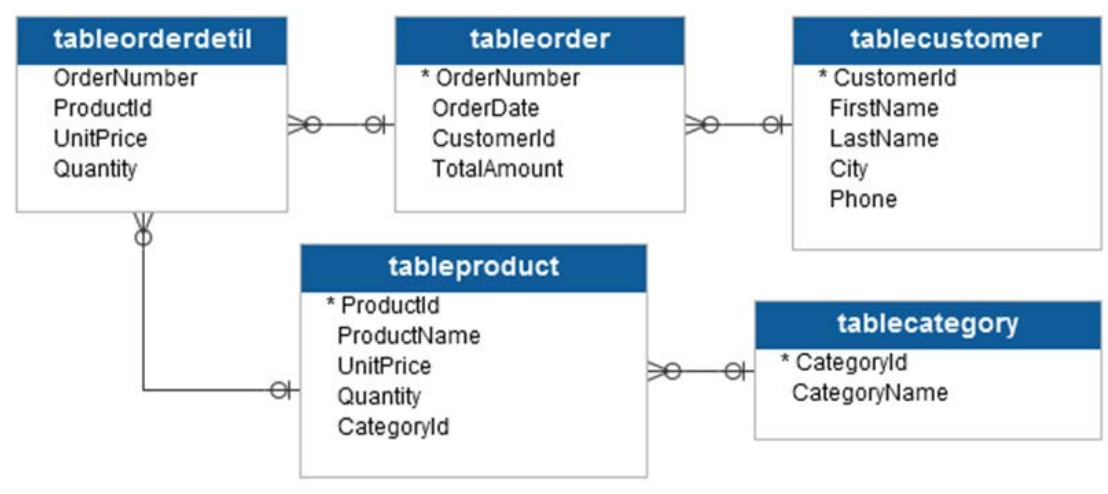

Gambar 6. Diagram Hubungan Entitas Mobile Retailing

Tahapan kegiatan implementasi merupakan kegiatan implementasi dari prototype sistem yang sudah buat dalam bentuk Graphical User Interface (GUI) yang sesuai dengan kebutuhan sistem. Merancang antarmuka merupakan bagian yang paling penting dari merancang sistem. Biasanya hal tersebut juga merupakan bagian yang paling sulit karena dalam merancang antarmuka harus memenuhi tiga persyaratan sebuah antarmuka yaitu sederhana, lengkap, dan harus memilki kinerja yang cepat. Pada tulisan ini hanya ditampilkan hasil rancangan yang ada pada antarmuka perangkat smartphone, sedangkan antarmuka dari sisi admin sebagai pemilik usaha tidak ditampilan.

\section{a. Rancangan Form Login}

Rancangan form login ditunjukkan pada Gambar 7 dipergunakan oleh konsumen untuk melakukan identifikasi data diri konsumen pada sistem. Data ini juga memberikan kemudahan bagi admin untuk mengetahui data konsumen yang memesan barang. Setiap konsumen wajib memiliki akun agar dapat menggunakan sistem ini untuk akvitas berbelanja.

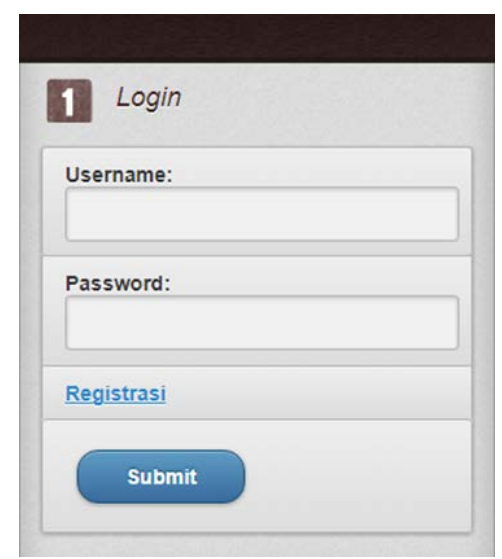

Gambar 7. Form Login

b. Rancangan Form Pilihan Menu

Rancangan form pilihan menu merupakan rancangan form yang dapat dipergunakan oleh konsumen untuk memilih aktivitas seperti mencari produk untuk dipesan dan menampilkan produk yang telah dibeli. Rancangan form pilihan menu ditunjukkan pada Gambar 8. 
Citec Journal, Vol. 4, No. 4, Agustus 2017 - Oktober 2017

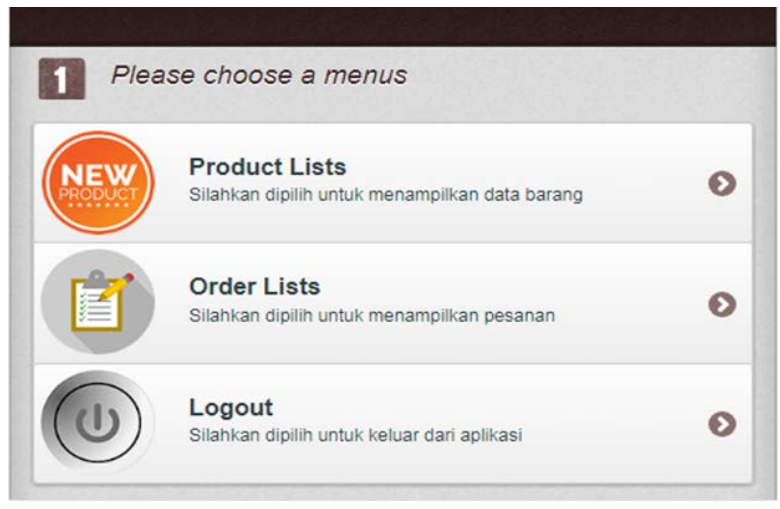

Gambar 8. Form Pilihan Menu

c. Rancangan Form Pilihan Produk

Rancangan form pilihan produk dipergunakan untuk menampilkan produk yang dimiliki oleh suatu pasar swalayan yang dilengkapi dengan pencarian data. Pencarian ini penting bagi konsumen untuk menemukan barang dengan mudah karena tidak semua produk dapat ditampilkan pada layar perangkat mobile seperti yang terlihat pada Gambar 9.

\begin{tabular}{|l|}
\hline 2 Please choose a product? \\
\hline 9 Filter items... \\
\hline ROMA Biscuit Kelapa \\
\hline Hollanda Wafer Krim Coklat \\
\hline Double Fress
\end{tabular}

Gambar 9. Form Pilihan Product

d. Rancangan Form Product Quantity

Hasil rancangan form product quantity dipergunakan oleh konsumen untuk menginputlan jumlah barang yang dipesan sesuai dengan nama barang yang telah dipilih pada Gambar 9 di atas. Hasil rancangan form product quantity bisa dilihat pada Gambar 10.

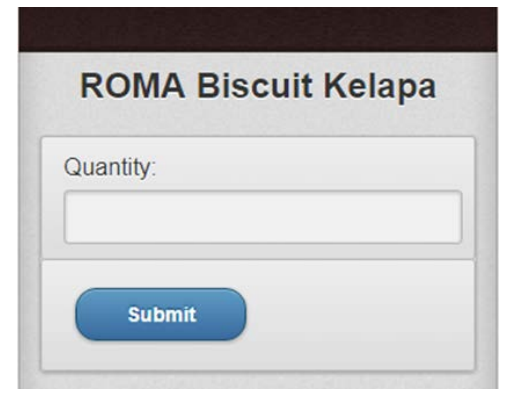

Gambar 10. Form Pilihan Product Quantity 
e. Rancangan Form Order List

Rancangan form order list yang ditunjukkan pada Gambar 11 dipergunakan untuk menampilkan data produk/barang yang telah dipesan oleh konsumen. Dengan form ini konsumen dapat melihat secara detil barang yang telah dipesan.

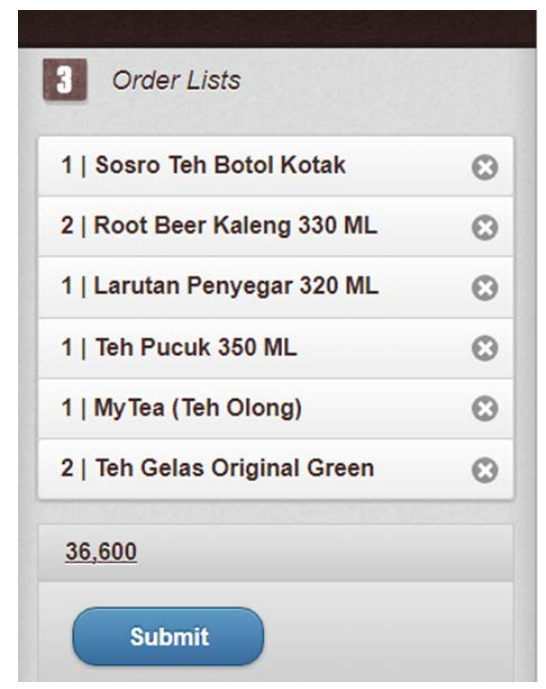

Gambar 11. Form Order Lists

Semua rancangan form yang ditampilkan disini merupakan hasil rancangan khusus sistem retailing yang diinstalkan pada perangkat smartphone. Data yang ditampilkan pada setiap form merupakan data simulasi dalam kegiatan implementasi sistem. Namun dengan data ini sudah mewakili dari data yang sesungguhnya.

\section{KESIMPULAN}

Bisnis akan sulit untuk bertumbuh bahkan untuk bisa bertahan secara keberlanjutan jika tidak didukung oleh penerapan teknologi informasi yang sesuai dan sejalan dengan kebutuhan bisnis perusahaan. Mengkombinasikan bisnis dengan penerapan teknologi informasi sudah menjadi kebutuhan pasar diera digitalisasi saat ini. Penggunaan teknologi mobile dalam mendukung kegiatan bisnis sudah menjadi tren diaat banyak orang memiliki mobilitas sangat tinggi. Berbelanja menggunakan perangkat mobile sudah menjadi hal yang biasa dikalangan masyaratkat, namun penggunaan perangkat mobile untuk kegiatan berbelanja kebutuhan seharihari di pasar swalayan masih belum terlihat. Tujuan penelitian ini adalah menghasilkan sistem mobile retailing yang dapat dipergunakan untuk berbelanja pada pasar swalayan. Sistem ini hanya dapat dipergunakan bagi masyarakat yang menggunakan perangkat smartphone. Dengan menggunakan Jquery Mobile Framework dan Web service, penelitian ini berhasil menghadir sistem mobile retailing dimana dengan sistem ini masyarakat dapat menggunakannya untuk memesan barang yang ada di salah satu toko swalayan. Metode pembayaran yang berlaku adalah Cash On Delivery dimana pembayaran dilakukan secara langsung oleh konsumen setelah konsumen mendapatkan barang yang dipesan dengan baik.

\section{SARAN}

Sistem mobile retailing perlu dikembangkan lebih lanjut terutama hal yang terkait dengan buat admin ketika konsumen sudah memesan barang dan juga notifikasi buat konsumen ketika barang yang sudah dipesan telah disetujui oleh admin. Pembahasan soal keamanan dan validasi pesanan juga merupakan hal yang menarik untuk dibahas lebih lanjut. 
6. Ucapan Terima Kasih

Penulis mengucapkan terima kasih kepada Sekolah Tinggi Manajemen Informatika dan Komputer (STMIK) Pontianak yang telah memberikan dukungan finansial terhadap penelitian ini. Terima kasih kepada rekan-rekan dosen yang telah memberikan masukan dan dukungan dalam menyelesaikan tulisan ini. Kepada para reviewer saya juga mengucapkan banyak terima kasih atas bimbingan dan arahannya sehingga tulisan ini dapat sesuai seperti apa yang diharapkan. Semoga tulisan ini dapat memberikan manfaat bagi banyak orang, saat ini maupun yang akan datang.

\section{DAFTAR PUSTAKA}

[1] Riasi., Pourmiri, S., 2015, Effects of online marketing on Iranian ecotourism industry: Economic, sociological, and cultural aspects, Management Science Letters, Vol. 5, No. 10, Hal 915-926.

[2] Balasubramanian, K., Balraj, A., Kumar, J., 2015, Customer Preference's to Select a Restaurant Through Smart Phone Applications: An Exploratory Study, Advanced Science Letters, Vol. 21, No. 5, Hal 1489-1493.

[3] Fandy, T., 2008, Strategi Pemasaran, ANDI, Yogyakarta.

[4] Chou, Y. C., Chuang, H. H. C., Shao, B. B., 2016, The impact of e-retail characteristics on initiating mobile retail services: A modular innovation perspective, Information \& Management, vol. 53, no. 4, Hal 481- 492.

[5] Bellini, S., Aiolfi, S., 2017, The Impact of Mobile Device Use on Shopper Behaviour in Store: An Empirical Research on Grocery Retailing, International Business Research, vol. 10, no. 4, Hal 58.

[6] Sohn, S., Seegebarth, B., Moritz, M., 2017, The Impact of Perceived Visual Complexity of Mobile Online Shops on User's Satisfaction, Psychology \& Marketing, vol. 34, no. 2, Hal 195-214.

[7] Mahapatra, S., Mahapatra, S., 2017, Mobile shopping among young consumers: an empirical study in an emerging market, International Journal of Retail \& Distribution Management, vol. 45, no. 9, Hal 930-949.

[8] Pantano, E., Priporas, C. V., 2016 The effect of mobile retailing on consumers' purchasing experiences: A dynamic perspective, Computers in human behavior, Vol. 61, Hal 548-555.

[9] Ahmad, A., 2016, Perancangan Aplikasi Komoditas Pertanian Berbasis Android, CSRID (Computer Science Research and Its Development Journal), Vol. 7, No. 3, Hal 190-200.

[10] Ahmad, S. U., Khan, M. S., 2017, An Exploratory Study on Effect of Demographic Factors on Consumer Satisfaction and its Determinants in E-Retailing, Management Studies and Economic Systems, vol. 3, no. 3, Hal 159-171.

[11] Zentes, J., Morschett, D., Klein, H. -S., 2017, Online Retailing, In Strategic Retail Management, Springer Fachmedien Wiesbaden, Hal 71-93.

[12] Halaweh, M., 2017, Intention to Adopt the Cash On Delivery (COD) Payment Model for E-commerce Transactions: An Empirical Study, In IFIP International Conference on Computer Information Systems and Industrial Management, Vol. 10244, Hal 628-637.

[13] Yadav, M. K., Rai, A. K., 2017, Exploring the Relational Impact of Service Quality on Customer Satisfaction, Ushus-Journal of Business Management, Vol. 4, No. 4, Hal 17-31. 
[14] Arifah, F. N., Rosidi, A., Al Fatta, H., 2013, Evaluasi Kepuasan Pelayanan Pengguna Aplikasi OPAC Perpustakaan STMIK AMIKOM Yogyakarta, Creative Information Technology Journal, Vol. 1, No. 1, Hal 46-56.

[15] Baskol, M., 2016, The Effects of E-Retail Service Quality on Repurchase Intention, Business and Economics Research Journal, Vol. 7, No. 4, Hal 107-121.

[16] Whitten, J. L., Bentley, L. D., Dittman, K. C., 2004, Systems Analysis and Design Methods: Sixth Edition, New York: McGraw-Hill/Irwin.

[17] Khan, A. I., Qurashi, R. J., Khan, U. A., 2011, A comprehensive study of commonly practiced heavy and light weight software methodologies, IJCSI International Journal of Computer Science Issues, Vol. 8, No. 2, Hal 144-450. 